\title{
More public health service providers are experiencing job burnout than clinical care providers in primary care facilities in China
}

Shan Lu ${ }^{1,2,3}$, Liang Zhang ${ }^{1,2^{*}}$, Niek Klazinga ${ }^{3}$ and Dionne Kringos ${ }^{3}$

\begin{abstract}
Background: Health workers are at high risk of job burnout. Primary care in China has recently expanded its scope of services to a broader range of public health services in addition to clinical care. This study aims to measure the prevalence of burnout and identify its associated factors among clinical care and public health service providers at primary care facilities.

Methods: A cross-sectional survey (2018) was conducted among 17,816 clinical care and public health service providers at 701 primary care facilities from six provinces. Burnout was measured by the Chinese version of the Maslach Burnout Inventory-General Scale, and multilevel linear regression analysis was conducted to identify burnout's association with demographics, as well as occupational and organisational factors.

Results: Overall, half of the providers (50.09\%) suffered from burnout. Both the presence of burnout and the proportion of severe burnout among public health service providers (58.06\% and 5.25\%) were higher than among clinical care providers (47.55\% and 2.26\%, respectively). Similar factors were associated with burnout between clinical care and public health service providers. Younger, male, lower-educated providers and providers with intermediate professional title, permanent contract or higher working hours were related to a higher level of burnout. Organisational environment, such as the presence of a performance-based salary system, affected job burnout.

Conclusions: Job burnout is prevalent among different types of primary care providers in China, indicating the need for actions that encompass the entirety of primary care. We recommend strengthening the synergy between clinical care and public health services and transforming the performance-based salary system into a more quality-based system that includes teamwork incentives.
\end{abstract}

Keywords: Burnout, Primary care, Clinical care providers, Public health service providers

\section{Background}

Strengthening primary care (PC) to improve health system outcomes is high on the health policy agenda of most countries, and this is expected to be further reinforced in the aftermath of the current COVID-19 pandemic [13]. This is also true for China. The Chinese government

*Correspondence: zhanglianghust@126.com

${ }^{1}$ School of Medicine and Health Management, Tongji Medical College, Huazhong University of Science and Technology, Wuhan 430030, China

Full list of author information is available at the end of the article launched a new round of healthcare reform in 2009, with priority given to the strengthening of $\mathrm{PC}$. Two out of five major reform programmes were directly related to PC. One of the programmes involved activities to construct PC facilities and to strengthen its workforce, and the other one re-established the importance of public health services within PC via the issuance of an essential package of services. As a result of this policy, PC services provided by $\mathrm{PC}$ facilities in China can be classified into two distinct categories, namely, basic clinical care (CC) and public health $(\mathrm{PH})$ services, which are financed by health 
insurance and direct government contributions, respectively. The achievement of strong PC is challenged by a shortage of PC providers. From 2009 to 2017, the number of PC providers in China increased from 1.83 to 2.51 million (1.37 to 1.80 PC providers per thousand population); the proportion of PC providers to the whole health system providers decreased from 36.43 to $30.22 \%$ during the same period, indicating the simultaneous reinforcement of secondary care $[4,5]$. In addition, the breadth and volume of the workload of basic $\mathrm{PH}$ services expanded, causing an imbalance with the size of the PH workforce, thereby posing a threat to professionals' health and quality of care [6]. The differences in roles and services delivery by clinical care and public health providers are presented in Additional file 1.

In the abovementioned context, an increasing amount of research has focused on solving retention problems and finding ways to improve the efficiency and productivity of providers, which may be affected by burnout of health workers. Health workers are at high risk of suffering from burnout, a risk that has only been increasing during the COVID-19 pandemic [7, 8]. Burnout among healthcare providers has been associated with adverse outcomes in patient care $[9,10]$, negative effects on the health worker's health [11], reduced physician productivity, higher turnover intention and reduced patient access [12-16]. The most widely used definition of burnout is that from Maslach and Jackson. They defined burnout as a psychological syndrome of emotional exhaustion (i.e. feelings of being emotionally overextended and depleted of one's emotional resource), depersonalisation (i.e. a negative, callous or excessively detached response to other people) and reduced personal accomplishment (i.e. a decline in one's feelings of competence and successful achievement in one's work), which can occur among individuals who work with other people [17].

Most of the previous studies on burnout among PC providers were conducted in other countries and across different type of providers (physicians, nurses, community health workers, midwives and pharmacists). The prevalence of burnout showed substantial variability across studies due to different measurements, target populations or contexts [18]. According to a systematic review published in 2018, the prevalence rates of emotional exhaustion, depersonalisation and decreased personal achievement were 27.4-99.6\%, 13.3-98.0\% and $25.1-99.3 \%$, respectively, among PC providers in low- and middle-income countries [3]. Contributors to provider burnout are as follows: work-related factors, including excessive workload, inefficient work process, payment model, work support and autonomy; and individual factors, including gender, age and level of education $[3,16]$. Incorporating a multilevel perspective into burnout research was argued to be more effective in confirming associated factors of burnout than focusing only at the individual level $[19,20]$.

Few studies have investigated burnout among PC providers in China [21-23]. Although these studies indicate an increased prevalence of burnout [21-23], they are limited as they mostly focus on a specific setting (e.g. township health centres representing rural areas or community health centres representing urban areas) [21, 22, $24,25]$ or on regional (e.g. city or provincial level) contexts $[19,26,27]$; these studies pay little attention to different types of PC providers and define PC providers by their job category as opposed to their type of service provision. This approach does not do justice to the different types of services that are currently provided in the Chinese PC system and limits our understanding of factors that contribute to burnout. To our knowledge, not much is known about the prevalence of burnout among $\mathrm{PC}$ providers that are involved in $\mathrm{CC}$ or $\mathrm{PH}$ services in China. Thus, this study aims to measure the prevalence of job burnout among $\mathrm{CC}$ and $\mathrm{PH}$ service providers in China, to identify the associated factors of job burnout for the two types of PC providers and to determine the strategies to mitigate burnout.

\section{Methods}

\section{Study design and sample}

This cross-sectional study was performed in 2018 in six provincial regions in China. A multistage stratified cluster sampling was used to determine the sample of PC facilities. The detailed sampling strategy is published elsewhere [6]. All PC providers from the sample PC facilities (including township and community health centres) were invited to participate in the survey.

Data were collected via an online survey in collaboration with local health bureaus from October 2018 to November 2018. The local health bureaus helped the study team communicate with the PC facilities, and the director of each facility forwarded the online questionnaire to PC providers. Before answering the questionnaire, all participants were assured de-identification and confidentiality in handling their data and consent to participate. The organisational information was also collected from the director of each PC facility through an online survey. In total, 23,778 PC providers in 741 PC facilities participated in the survey. The response rate was $90.0 \%$ (23,778 out of 26,417). Cases with missing data in the surveys (209 cases in the provider survey and 753 cases on organisational information) or with wrong information (1057 cases with wrong facility name) were excluded. The final sample size was $21,759 \mathrm{PC}$ providers from $708 \mathrm{PC}$ facilities. The effective response rate was $82.4 \%(21,759$ out of 26,417$)$. 


\section{Clinical care and public health service providers}

In general, the daily work of PC providers includes service delivery and administrative work. Service delivery includes $\mathrm{CC}$ and $\mathrm{PH}$ services, and administrative work is only performed by some providers who hold an administrative position, e.g. (vice) director of the facility or head of a department in the facility. PC providers in China include doctors, nurses, pharmacists, clinical laboratory technicians and imaging technicians. Some of these providers undertake multiple positions or types of services. In the survey, participants were asked to estimate the average percentage of their working hours spent on $\mathrm{CC}$ service delivery, $\mathrm{PH}$ service delivery, traditional Chinese medicine service delivery and administrative work on a yearly basis. Given that traditional Chinese medicine services belong to $\mathrm{CC}$, and the working hours of $\mathrm{CC}$ providers who only provide western medicine and those who only provide traditional Chinese medicine are the same at PC facilities, $\mathrm{CC}$ and traditional Chinese medicine service delivery were merged in this study. The participants were classified according to the estimated percentage of time they reportedly dedicate to three types of work, namely, CC service delivery, $\mathrm{PH}$ service delivery and administrative work. Those participants who dedicated more of their time to CC delivery than the other two types of work were included as CC providers $(n=13,512)$ in this study. Similarly, PH service providers $(n=4304)$ and administrative professionals $(n=1170)$ were determined and grouped. The average percentage of time spent in $\mathrm{CC}$ and $\mathrm{PH}$ service delivery in the $\mathrm{CC}$ and $\mathrm{PH}$ service groups were $77.7 \%$ and $78.2 \%$, respectively. The distribution of the percentage for the groups is described in Additional file 2. The administrative group and participants who dedicated a large portion of their time equally to at least two of the three types of work $(n=973)$ and whose answers summed up larger than $100 \%(n=1800)$ were excluded from this study. Overall, $\mathrm{CC}$ and $\mathrm{PH}$ service providers $(n=17,816)$ from $701 \mathrm{PC}$ facilities were included in the analysis.

\section{Measures}

\section{Burnout}

The Chinese version of the Maslach Burnout InventoryGeneral Survey (MBI-GS) was used, which was first introduced in 2002 [28] and has shown good reliability and validity in previous studies [21, 29, 30]. The 15-item scale measures three dimensions of job burnout, with 5 items for emotional exhaustion, 4 items for depersonalisation and 6 items for reduced personal accomplishment. Each item of the MBI-GS includes a 7-point Likert scale ranging from 0 ("never") to 6 ("every day"). A high score for emotional exhaustion and depersonalisation and a low score for reduced personal accomplishment indicate more severe burnout. Therefore, the 6 items for reduced personal accomplishment were reversely scored. The following equation (1) was adopted to calculate the weighted sum score of burnout in consistency with other studies [29, 31, 32]:

$$
\begin{aligned}
\text { Burnout }= & (0.4 * \text { emotional exhaustion } \\
& +0.3 * \text { depersonalisation } \\
& +0.3 * \text { reduced personal } \\
& \text { accomplishment }) / 15 .
\end{aligned}
$$

Cut-off points adopted by previous studies were used to classify the participants into the three following groups based on their score [31,32], namely, group 1no burnout (0-1.49), group 2-moderate burnout (1.503.49) and group 3-severe burnout (3.5-6.0). The criteria used to indicate the presence of emotional exhaustion, depersonalisation and reduced personal accomplishment were the average score of the items for subcomponents $\geq 3.2,>2.2$ and $\leq 4.0$, respectively [33].

\section{Associated factors of burnout}

The associated factors included in this study can be divided into three categories, namely, demographics, occupational factors and organisational factors. The definitions and categories of the associated factors are shown in Table 1.

\section{Statistical analysis}

The $t$-test and Chi-square test were used to compare the characteristics, burnout and its subcomponents scores between CC and PH service providers in Stata 15. Multilevel linear regression analysis was conducted to identify the associated factors of job burnout for $\mathrm{CC}$ and $\mathrm{PH}$ service providers in Stata 15, respectively. The dependent variables were the weighted sum score of burnout and the average score of each subcomponent. The null model (i.e. intercept-only model) was first generated for each dependent variable to test the existence of sufficient variance at the cluster level in influencing burnout. The interclass correlation coefficient was computed. Then, the full model, which was a two-level random intercept linear regression model with level one predictors (i.e. demographics and occupational factors) and level two predictors (i.e. organisational factors), was constructed. Goodness-of-fit of the models were examined by the log likelihood-ratio test. The multicollinearity between the predictors was evaluated by variance inflation factors, which demonstrated the existence of multicollinearity if larger than 10. 
Table 1 Definitions and categories of the associated factors

\begin{tabular}{|c|c|}
\hline Factors & Definitions and categories \\
\hline \multicolumn{2}{|l|}{ Demographics } \\
\hline $\mathrm{Age}^{*}$ & Age of the participant \\
\hline Gender & $\begin{array}{l}\text { Gender of the participant } \\
0=\text { male, } 1=\text { female }\end{array}$ \\
\hline Marital status & $\begin{array}{l}\text { Marital status of the participant } \\
0=\text { married, } 1=\text { unmarried (including single, divorced or widowed) }\end{array}$ \\
\hline Education level & $\begin{array}{l}\text { Education level of the participant } \\
0=\text { junior college or below, } 1=\text { undergraduates, } 2=\text { postgraduates }\end{array}$ \\
\hline \multicolumn{2}{|l|}{ Occupational factors } \\
\hline Job type & $\begin{array}{l}\text { Job type of the participant } \\
0=\text { doctors, } 1=\text { nurses, } 2=\text { pharmacist, } 3=\text { others }\end{array}$ \\
\hline Title & $\begin{array}{l}\text { The rank of a professional post } \\
0=\text { junior or no title, } 1=\text { intermediate, } 2=\text { senior }\end{array}$ \\
\hline Administrative responsibility & $\begin{array}{l}\text { If the participant has administrative responsibility or not } \\
0=\text { yes, } 1=\text { no }\end{array}$ \\
\hline Employment status & $\begin{array}{l}\text { The employment status of the participant } \\
0=\text { permanent, } 1=\text { temporary (including providers with temporary contracts and those rehired after retirement) }\end{array}$ \\
\hline Working years* & Working years in current facility \\
\hline Working hours & $\begin{array}{l}\text { Working hours per week of the participant } \\
0=<40,1=40-49,2=50-59,3 \geq 60\end{array}$ \\
\hline Income proportion & $\begin{array}{l}\text { Proportion of the participant's income to the total household income } \\
0=<25 \%, 1=25-49 \%, 2=50-75 \%, 3=\geq 75 \%\end{array}$ \\
\hline \multicolumn{2}{|l|}{ Organisational factors } \\
\hline Location & $\begin{array}{l}\text { Location of the facility } \\
0=\text { eastern, } 1=\text { central, } 2=\text { western }\end{array}$ \\
\hline Facility type & $\begin{array}{l}\text { Type of the facility } \\
0=\text { township health centre (representing rural areas), } 1=\text { community health centre (representing urban areas) }\end{array}$ \\
\hline Performance-based salary* & $\begin{array}{l}\text { The ratio of performance-based salary of the facility. The salary of PC facilities in China consisted of two parts, } \\
\text { namely, the fixed and the fluctuating parts. The fluctuating part is performance-based salary }\end{array}$ \\
\hline
\end{tabular}

* Continuous variables

\section{Results}

\section{Study participants and facilities}

In total, 17,816 CC and PH service providers from 701 PC facilities were included in this study. Table 2 presents the description of participants and facilities. Among sample facilities, $45 \%, 21 \%$ and $34 \%$ were from eastern, central and western China, respectively, which were consistent with the national data (41\%, $27 \%$ and $31 \%$, respectively). The average age of the overall participants was 35 years old, and $70 \%$ of them were female. The results of Chisquare and t-test showed that the differences between $\mathrm{CC}$ and $\mathrm{PH}$ service providers for most individual characteristics (except for age, marital status and income proportion) were statistically significant $(p<0.05)$. Compared with the CC group, more women (75\% vs $69 \%$ ), more providers who graduated from junior college or below ( $61 \%$ vs $58 \%$ ), fewer providers with junior or senior title $(26 \%$ vs $31 \%)$, fewer providers with administrative responsibilities (30\% vs $33 \%$ ), less average working years (9.01 vs 9.15) and fewer providers working more than $50 \mathrm{~h}$ per week (30\% vs $45 \%$ ) were in the $\mathrm{PH}$ service group.

\section{Prevalence of job burnout}

Table 3 shows the prevalence of job burnout and the three subcomponents among $\mathrm{CC}$ and $\mathrm{PH}$ service providers. Overall, half of the providers (50.09\%) suffered from burnout, and $2.99 \%$ of the providers had severe burnout. The presence of burnout and the proportion of severe burnout in the PH service group (58.06\% and 5.25\%) were higher than those in the CC group $(47.55 \%$ and $2.26 \%$, respectively). The prevalence of reduced personal accomplishment (40.85\%) was larger than those of emotional exhaustion (14.60\%) and depersonalisation (13.20\%) among overall providers, and the prevalence of all three subcomponents among $\mathrm{PH}$ service providers was larger than among CC providers.

Table 4 presents the average scores of burnout and its three subcomponents among $\mathrm{CC}$ and $\mathrm{PH}$ service providers. According to the results of $t$-tests, all scores (including weighted sum score of burnout and scores of the three subcomponents) of $\mathrm{PH}$ service providers were higher than the scores of $\mathrm{CC}$ providers. 
Table 2 Description of the participants $(n=17,816)$ and facilities $(n=701)$

\begin{tabular}{|c|c|c|c|c|c|c|c|}
\hline & \multicolumn{2}{|c|}{ Overall } & \multicolumn{2}{|l|}{ CC } & \multicolumn{2}{|l|}{$\mathrm{PH}$} & \multirow[t]{2}{*}{$p$-value } \\
\hline & $N$ & $\%$ & $N$ & $\%$ & $N$ & $\%$ & \\
\hline \multicolumn{8}{|l|}{ Individual } \\
\hline $\begin{array}{l}\text { Age } \\
\text { (mean, SD) }\end{array}$ & 35.39 & 9.27 & 35.42 & 9.40 & 35.30 & 8.84 & $0.467^{*}$ \\
\hline \multicolumn{8}{|l|}{ Gender } \\
\hline Male & 5312 & 29.82 & 4239 & 31.37 & 1073 & 24.93 & $<0.001^{\dagger}$ \\
\hline Female & 12,504 & 70.18 & 9273 & 68.63 & 3231 & 75.07 & \\
\hline \multicolumn{8}{|l|}{ Marital status } \\
\hline Married & 14,095 & 79.11 & 10,658 & 78.88 & 3437 & 79.86 & $0.169^{\dagger}$ \\
\hline Unmarried & 3721 & 20.89 & 2854 & 21.12 & 867 & 20.14 & \\
\hline \multicolumn{8}{|l|}{ Education level } \\
\hline Junior college or below & 10,479 & 58.82 & 7873 & 58.27 & 2606 & 60.55 & $0.016^{\dagger}$ \\
\hline Undergraduates & 7181 & 40.31 & 5525 & 40.89 & 1656 & 38.48 & \\
\hline Postgraduates & 156 & 0.88 & 114 & 0.84 & 42 & 0.98 & \\
\hline \multicolumn{8}{|l|}{ Job type } \\
\hline Doctor & 8421 & 47.27 & 5767 & 42.68 & 2654 & 61.66 & $<0.001^{\dagger}$ \\
\hline Nurse & 5343 & 29.99 & 4244 & 31.41 & 1099 & 25.53 & \\
\hline Pharmacist & 1266 & 7.11 & 1117 & 8.27 & 149 & 3.46 & \\
\hline Others & 2786 & 15.64 & 2384 & 17.64 & 402 & 9.34 & \\
\hline \multicolumn{8}{|l|}{ Title } \\
\hline Primary & 12,452 & 69.89 & 9266 & 68.58 & 3186 & 74.02 & $<0.001^{\dagger}$ \\
\hline Junior & 4623 & 25.95 & 3619 & 26.78 & 1004 & 23.33 & \\
\hline Senior & 741 & 4.16 & 627 & 4.64 & 114 & 2.65 & \\
\hline \multicolumn{8}{|l|}{ Administrative responsibility } \\
\hline Yes & 5780 & 32.44 & 4501 & 33.31 & 1279 & 29.72 & $<0.001^{\dagger}$ \\
\hline No & 12,036 & 67.56 & 9011 & 66.69 & 3025 & 70.28 & \\
\hline \multicolumn{8}{|l|}{ Employment status } \\
\hline Long term & 12,920 & 72.52 & 9723 & 71.96 & 3197 & 74.28 & $0.003^{\dagger}$ \\
\hline Temporary & 4896 & 27.48 & 3789 & 28.04 & 1107 & 25.72 & \\
\hline Working years (mean, SD) & 10.03 & 9.12 & 10.16 & 9.15 & 9.64 & 9.01 & $0.001^{*}$ \\
\hline \multicolumn{8}{|l|}{ Working hours } \\
\hline$<40$ & 1556 & 8.73 & 1156 & 8.56 & 400 & 9.29 & $<0.001^{\dagger}$ \\
\hline $40-49$ & 8867 & 49.77 & 6249 & 46.25 & 2618 & 60.83 & \\
\hline $50-59$ & 3892 & 21.85 & 3029 & 22.42 & 863 & 20.05 & \\
\hline$\geq 60$ & 3501 & 19.65 & 3078 & 22.78 & 423 & 9.83 & \\
\hline \multicolumn{8}{|l|}{ Income proportion } \\
\hline$<25 \%$ & 3365 & 18.89 & 2530 & 18.72 & 835 & 19.4 & $0.265^{\dagger}$ \\
\hline $25 \%-49 \%$ & 5289 & 29.69 & 3981 & 29.46 & 1308 & 30.39 & \\
\hline $50 \%-75 \%$ & 5718 & 32.09 & 4354 & 32.22 & 1364 & 31.69 & \\
\hline$>75 \%$ & 3444 & 19.33 & 2647 & 19.59 & 797 & 18.52 & \\
\hline \multicolumn{8}{|l|}{ Facility } \\
\hline \multicolumn{8}{|l|}{ Location } \\
\hline Eastern & 315 & 44.94 & - & & & & \\
\hline Central & 148 & 21.11 & - & & & & \\
\hline Western & 238 & 33.95 & - & & & & \\
\hline \multicolumn{8}{|l|}{ Facility type } \\
\hline Township health centre & 420 & 59.91 & - & & & & \\
\hline Community health centre & 281 & 40.09 & - & & & & \\
\hline Performance-based salary (mean, SD) & 37.28 & 18.68 & - & & & & \\
\hline
\end{tabular}

${ }^{*} p$ value of $t$-test to examine the significance of difference in the variable between clinical care and public health service groups

${ }^{\dagger} p$ value of Chi-square test to examine the significance of difference in the variable between clinical care and public health service groups 
Table 3 Prevalence of job burnout and the subcomponents among clinical care (CC) and public health (PH) service providers

\begin{tabular}{|c|c|c|c|c|c|c|}
\hline \multirow[t]{2}{*}{ Degree } & \multicolumn{2}{|c|}{ Overall $(N=17,816)$} & \multicolumn{2}{|c|}{$\mathrm{CC}(N=13,512)$} & \multicolumn{2}{|c|}{$\mathrm{PH}(N=4304)$} \\
\hline & $N$ & $\%$ & $N$ & $\%$ & $N$ & $\%$ \\
\hline \multicolumn{7}{|l|}{ Job burnout } \\
\hline No burnout & 8892 & 49.91 & 7087 & 52.45 & 1805 & 41.94 \\
\hline Moderate burnout & 8392 & 47.10 & 6119 & 45.29 & 2273 & 52.81 \\
\hline Severe burnout & 532 & 2.99 & 306 & 2.26 & 226 & 5.25 \\
\hline \multicolumn{7}{|l|}{ Subcomponents } \\
\hline Emotional exhaustion & 2602 & 14.60 & 1776 & 13.14 & 826 & 19.19 \\
\hline Depersonalisation & 2351 & 13.20 & 1571 & 11.63 & 780 & 18.12 \\
\hline Reduced personal accomplishment & 7278 & 40.85 & 5256 & 38.90 & 2022 & 46.98 \\
\hline
\end{tabular}

Table 4 Burnout scores among clinical care (CC) and public health (PH) service providers

\begin{tabular}{|c|c|c|c|c|c|c|c|}
\hline \multirow[t]{2}{*}{ Degree } & \multicolumn{2}{|c|}{ Overall $(N=17,816)$} & \multicolumn{2}{|c|}{$\mathrm{CC}(N=13,512)$} & \multicolumn{2}{|c|}{$\mathrm{PH}(N=4304)$} & \multirow[t]{2}{*}{$p$ value $^{a}$} \\
\hline & Mean & SD & Mean & SD & Mean & SD & \\
\hline Weighted sum score of burnout & 1.58 & 0.95 & 1.51 & 0.92 & 1.77 & 1.02 & $<0.001$ \\
\hline Emotional exhaustion & 1.95 & 1.28 & 1.89 & 1.25 & 2.15 & 1.34 & $<0.001$ \\
\hline Depersonalisation & 1.03 & 1.09 & 0.97 & 1.05 & 1.21 & 1.19 & $<0.001$ \\
\hline Reduced personal accomplishment ${ }^{b}$ & 4.38 & 1.36 & 4.44 & 1.36 & 4.19 & 1.38 & $<0.001$ \\
\hline
\end{tabular}

${ }^{a} p$ value of t-test to examine the significance of difference in the variable between clinical care and public health service groups

b The scores of items of reduced personal accomplishment were not reversed in the analysis of single dimension

\section{Factors associated with job burnout}

The intra-class correlation coefficient in the null model and the goodness-of-fit indicator for each dependent variable were presented in Additional file 3. For the 8 dependent variables, including the weighted sum score of burnout and the average score of each subcomponent for the $\mathrm{CC}$ and $\mathrm{PH}$ service groups separately, the intra-class correlation coefficients ranged from 0.07 to 0.2 , which were all larger than 0.059 . The tests of the preference of log likelihood versus linear regression were also strongly significant $(p<0.001)$, indicating that the multilevel linear regression was appropriate. The variance inflation factor for each predictor was smaller than 10, which demonstrated the absence of multicollinearity.

\section{Demographics}

Table 5 shows factors associated with burnout and its three subcomponents for $\mathrm{CC}$ and $\mathrm{PH}$ service providers. Age was negatively associated with burnout, emotional exhaustion, depersonalisation and reduced personal accomplishment in both groups $(p<0.05)$, except for emotional exhaustion in the $\mathrm{PH}$ service group $(p>0.05)$. Similarly, female providers showed a lower level of burnout and its subcomponents in both groups $(p<0.05)$, except for emotional exhaustion in the $\mathrm{PH}$ service group $(p>0.05)$. Marital status was not associated with burnout $(p>0.05)$, but unmarried providers indicated a lower degree of emotional exhaustion and personal accomplishment in the CC group $(p<0.05)$. Higher educational degree was related to a higher level of burnout, emotional exhaustion and depersonalisation in CC group $(p<0.05)$, while for $\mathrm{PH}$ service group, providers with the highest educational degree (postgraduates) showed no difference compared with providers with the lowest degree (junior college or below).

\section{Occupational factors}

Doctors were related to a higher degree of burnout than other job types $(p<0.05)$ in both groups. Compared with providers with junior or no title, providers with intermediate title in both groups showed a higher level of burnout $(p<0.05)$, whereas senior providers showed no difference in both groups $(p>0.05)$. Providers in both groups with temporary contract showed a lower level of burnout $(p<0.05)$ compared with permanent providers, as well as lower emotional exhaustion and depersonalisation $(p<0.05)$. Working hours were positively associated with the level of burnout, emotional exhaustion and depersonalisation for $\mathrm{CC}$ providers $(p<0.05)$ and with the level of burnout, emotional 
Table 5 Factors associated with burnout and its subcomponents for clinical care and public health service providers

\begin{tabular}{|c|c|c|c|c|c|c|c|c|}
\hline & \multicolumn{4}{|c|}{ Clinical care } & \multicolumn{4}{|c|}{ Public health services } \\
\hline & Burnout & $\mathrm{EE}$ & DP & $\mathrm{PA}^{\mathrm{a}}$ & Burnout & $\mathrm{EE}$ & DP & $\mathrm{PA}^{\mathrm{a}}$ \\
\hline Age & $-0.010^{* *}$ & $-0.005^{* *}$ & $-0.010^{* *}$ & $0.018^{* *}$ & $-0.012^{* *}$ & -0.002 & $-0.009^{* *}$ & $0.026^{* *}$ \\
\hline \multicolumn{9}{|l|}{ Gender (ref: male) } \\
\hline Female & $-0.074^{* *}$ & $-0.068^{* *}$ & $-0.066^{* *}$ & $0.089 * *$ & $-0.100^{* *}$ & -0.052 & $-0.118^{* *}$ & $0.142^{* *}$ \\
\hline \multicolumn{9}{|l|}{ Marital (ref: married) } \\
\hline Unmarried & 0.002 & $-0.092^{* *}$ & 0.034 & $-0.102^{* *}$ & 0.031 & -0.027 & 0.069 & -0.084 \\
\hline \multicolumn{9}{|c|}{ Education (ref: junior college or below) } \\
\hline Undergraduates & $0.074^{* *}$ & $0.173^{* *}$ & $0.121^{* *}$ & $0.099^{* *}$ & $0.078^{* *}$ & $0.145^{* *}$ & $0.120 * *$ & 0.041 \\
\hline Postgraduates & $0.266^{* *}$ & $0.262^{* *}$ & $0.428^{* *}$ & -0.114 & 0.217 & 0.186 & 0.219 & -0.286 \\
\hline \multicolumn{9}{|l|}{ Job type (ref: doctor) } \\
\hline Nurse & $-0.074^{* *}$ & $-0.089^{* *}$ & $-0.054^{* *}$ & $0.073^{* *}$ & $-0.143^{* *}$ & $-0.137^{* *}$ & $-0.141^{* *}$ & $0.161^{* *}$ \\
\hline Pharmacist & $-0.191^{* *}$ & $-0.279^{* *}$ & $-0.165^{* *}$ & $0.100 * *$ & $-0.205^{* *}$ & -0.145 & $-0.171^{*}$ & $0.321^{* *}$ \\
\hline Others & $-0.163^{* *}$ & $-0.178^{* *}$ & $-0.160^{* *}$ & $0.147^{* *}$ & $-0.109^{* *}$ & $-0.173^{* *}$ & -0.070 & 0.071 \\
\hline \multicolumn{9}{|l|}{ Title (ref: junior or no title) } \\
\hline Intermediate & $0.113^{* *}$ & $0.204^{* *}$ & $0.123^{* *}$ & 0.011 & $0.202^{* *}$ & $0.246^{* *}$ & $0.248^{* *}$ & $-0.107^{*}$ \\
\hline Senior & $0.072^{*}$ & $0.135^{* *}$ & $0.091^{* *}$ & 0.021 & 0.054 & 0.122 & 0.169 & 0.168 \\
\hline \multicolumn{9}{|c|}{ Administrative responsibility (ref: yes) } \\
\hline No & $0.073^{* *}$ & $0.045^{* *}$ & $0.103^{* *}$ & $-0.085^{* *}$ & 0.032 & -0.055 & $0.088^{* *}$ & $-0.092^{* *}$ \\
\hline \multicolumn{9}{|c|}{ Employment status (ref: permanent) } \\
\hline Temporary & $-0.089^{* *}$ & $-0.129^{* *}$ & $-0.071^{* *}$ & 0.042 & $-0.104^{* *}$ & $-0.164^{* *}$ & $-0.121^{* *}$ & -0.007 \\
\hline Working years & $0.002^{*}$ & 0.002 & 0.003 & -0.002 & 0.001 & 0.002 & -0.003 & -0.003 \\
\hline \multicolumn{9}{|l|}{ Working hours (ref:<40) } \\
\hline $40-49$ & $0.091^{* *}$ & $0.199^{* *}$ & $0.088^{* *}$ & 0.047 & 0.033 & $0.220^{* *}$ & 0.026 & $0.203^{* *}$ \\
\hline $50-59$ & $0.206^{* *}$ & $0.418^{* *}$ & $0.162^{* *}$ & 0.029 & $0.161^{* *}$ & $0.490^{* *}$ & 0.105 & $0.212^{* *}$ \\
\hline$\geq 60$ & $0.348^{* *}$ & $0.775^{* *}$ & $0.261^{* *}$ & $0.133^{* *}$ & $0.426^{* *}$ & $0.954^{* *}$ & $0.408^{* *}$ & $0.254^{* *}$ \\
\hline \multicolumn{9}{|c|}{ Income proportion (ref:<25\%) } \\
\hline $25-49 \%$ & $-0.105^{* *}$ & $-0.115^{* *}$ & $-0.113^{* *}$ & $0.082^{* *}$ & $-0.138^{* *}$ & $-0.162^{* *}$ & $-0.187^{* *}$ & 0.062 \\
\hline $50-75 \%$ & -0.034 & 0.037 & $-0.058^{* *}$ & $0.098^{* *}$ & -0.047 & 0.001 & -0.072 & 0.074 \\
\hline$>75 \%$ & 0.029 & $0.207^{* *}$ & 0.002 & $0.172^{* *}$ & 0.012 & $0.145^{* *}$ & -0.018 & $0.120^{*}$ \\
\hline \multicolumn{9}{|l|}{ Location (ref: eastern) } \\
\hline Central & $-0.145^{* *}$ & $-0.156^{* *}$ & $-0.141^{* *}$ & $0.109^{* *}$ & $-0.218^{* *}$ & $-0.330^{* *}$ & $-0.260^{* *}$ & 0.006 \\
\hline Western & 0.036 & $-0.084^{* *}$ & 0.036 & $-0.212^{* *}$ & 0.090 & 0.016 & -0.056 & $-0.354^{* *}$ \\
\hline \multicolumn{9}{|c|}{ Facility type (ref: township health centre) } \\
\hline Community health centre & $0.155^{* *}$ & $0.183^{* *}$ & $0.135^{* *}$ & $-0.140^{* *}$ & $0.154^{* *}$ & $0.251^{* *}$ & $0.127^{* *}$ & -0.043 \\
\hline Performance-based salary & $0.003^{* *}$ & $0.004^{* *}$ & $0.003^{* *}$ & -0.001 & $0.003^{* *}$ & $0.004^{* *}$ & $0.003^{* *}$ & -0.001 \\
\hline Constant & $1.664^{* *}$ & $1.553^{* *}$ & $1.078^{* *}$ & $3.651^{* *}$ & $2.053^{* *}$ & $1.828^{* *}$ & $1.505^{* *}$ & $3.146^{* *}$ \\
\hline
\end{tabular}

${ }^{* *} p<0.05,{ }^{*} p<0.1$

a The scores of items of reduced personal accomplishment were not reversed in the analysis of single dimension

exhaustion and personal accomplishment for $\mathrm{PH}$ service providers $(p<0.05)$.

\section{Organisational factors}

For facility-level factors, community health centres predicted a higher level of burnout, emotional exhaustion, depersonalisation and reduced personal accomplishment in both groups $(p<0.05)$, except for reduced personal accomplishment in the PH service group $(p>0.05)$. Performance-based salary was positively associated with burnout, emotional exhaustion and depersonalisation in both groups $(p<0.05)$. Comparing with $\mathrm{PC}$ facilities from eastern China, those from central China showed a lower level of burnout $(p<0.05)$, whereas those from western China showed no difference $(p>0.05)$. 


\section{Discussion}

This study aimed to measure the prevalence of job burnout and identify its associated factors among $\mathrm{CC}$ and $\mathrm{PH}$ service providers at $\mathrm{PC}$ facilities in China. Half of the providers suffered from burnout, and more $\mathrm{PH}$ service providers showed moderate or severe burnout than CC providers. Similar factors were related to job burnout between the two provider groups, including demographics (age, gender and education level), occupational (job type, professional title and working hours) and organisational factors (location, facility type and performancebased salary).

This study showed that the self-reported prevalence of burnout among PC providers in 2018 was 50.09\%, indicating that burnout is prevalent in $\mathrm{PC}$ facilities in China. This result is consistent with those of previous smallscale studies on job burnout among Chinese PC providers, as measured by MBI-GS, although the prevalence rate of burnout in our study was higher than those in previous studies (27.8 to $39.7 \%$ ) conducted between 2010 and 2015 [23, 34-36]. This may indicate an increasing trend of burnout among PC providers in China. Despite the policy focus on strengthening $\mathrm{PC}$, we have observed a decreasing proportion of $\mathrm{PC}$ workforce to the overall health system workforce in China; moreover, shortage of workforce has been reported [37-39], whereas task profiles of PC staff have been largely expanded under recent reforms. This increase in experienced workload of PC providers may lead to burnout. The prevalence of moderate burnout in this study $(47.1 \%)$ is much lower than that $(70.25 \%)$ shown by a recent published study from Hubei Province, China [26], which may be due to the study scale (national vs. regional) or the different instruments adopted (MBI-GS vs. MBI-HSS) to measure burnout. The results of this current study demonstrated that the prevalence of reduced personal accomplishment was higher than that of the other two subcomponents, which is in line with the results of previous studies conducted at Chinese PC facilities [19, 26, 33]. Reported low levels of personal accomplishment among Chinese PC providers might be explained by the fact that citizens are free to choose their first-contact health care facility; they generally have little trust in PC and usually bypass PC facilities to seek health care in hospitals [19]. Specifically, the prevalence rates of emotional exhaustion (14.60\%) and depersonalisation (13.20\%) in this study were lower than their counterparts in low- and middle-income countries (27.4-99.6\% and 13.3-98.0\%, respectively), whereas those of reduced personal accomplishment (40.85\%) was within the range of $25.1-99.3 \%$ [3].

The reported prevalence rates of burnout and its subcomponents among $\mathrm{PH}$ service providers were higher than those of $\mathrm{CC}$ providers. One possible explanation is that $\mathrm{PH}$ service providers accept more workload and spend more time on administrative tasks (e.g. filling up health records and follow-up forms), which are not the most rewarding tasks [40, 41]. Our previous study showed that the volume-based output of $\mathrm{PH}$ service providers was increasingly larger than that of CC service providers in 2009-2015, but the gap became slightly smaller after 2015; the output of PH service providers still remains 4.6 times that of $\mathrm{CC}$ service providers [6]. Thus far, $\mathrm{CC}$ and $\mathrm{PH}$ services at $\mathrm{PC}$ facilities in China are relatively fragmented in terms of service delivery (i.e. providers in charge of different services seldom communicate with one another [42]) and financing system (i.e. health insurance schemes cover basic CC, whereas government subsidies finance basic $\mathrm{PH}$ services), which may hinder the distributive justice of work between the two service groups and the collaborative and friendly working environment. Studies have confirmed the impact of distributive justice and working environment on job burnout $[3,16,28]$, which will ultimately affect the improvement in health outcomes for patients-the core objective of the primary health care system. Therefore, the $\mathrm{PH}$ service providers need to receive more attention, and the synergy between $\mathrm{CC}$ and $\mathrm{PH}$ services needs to be strengthened by increasing flexibility in care substitution, enhancing team-based work and integrating the financing systems.

Overall, similar factors seemed to be associated with job burnout between $\mathrm{CC}$ and $\mathrm{PH}$ service groups in this study, with only a few exceptions. In accordance with previous studies, age was negatively related to burnout, and this can be explained by the classical Job DemandsResources model. The lack of resources to cope with demanding situations at work was associated with depersonalisation and reduced personal efficacy [43]. In general, younger health care workers have less work experience, network support and work autonomy [44, 45], which may result in job burnout and the appearance of symptoms of burnout subcomponents among early age PC providers. Male providers reported a higher level of burnout, which is in line with the findings of a recent study that focused on Chinese PC providers [19]. With higher expectations and stress, providers with higher education background were more likely to suffer from burnout [45]. Different from the CC group, the burnout scores of postgraduates from $\mathrm{PH}$ service group were not significantly distinct from the reference (i.e. junior college or below), which may be due to the smaller sample size $(n=42)$.

Doctors, providers with intermediate professional title and providers with a permanent contract and more working hours, reported a higher level of burnout. Interestingly, providers with intermediate professional titles were more likely to show burnout than the reference (i.e. 
junior or no title), but the senior providers showed no difference from the reference. Although the senior providers presented a higher degree of emotional exhaustion and depersonalisation, the coefficients $(0.135$ and 0.091$)$ were still smaller than those of the intermediate group $(0.204$ and 0.123 , respectively). One explanation may be that providers with an intermediate title are generally in the promotion period of their career when their ambitions, competition stress and even unmet expectations may all lead to burnout. As expected, the longer their working hours per week, the higher the level of burnout of the PC providers. More than $90 \%$ of providers in both CC and $\mathrm{PH}$ service groups worked more than $40 \mathrm{~h}$ per week, and $22.78 \%$ of $\mathrm{CC}$ and $9.83 \%$ of $\mathrm{PH}$ service providers worked more than $60 \mathrm{~h}$ per week, indicating that the shortage of workforce and the inefficiency of care delivery in the PC system need to be addressed. Another interesting result of this study was that more working hours were associated with high personal accomplishment, which needs to be further confirmed, as some studies suggested that the dimension of reduced personal accomplishment is not as important as the other two dimensions in explaining job burnout and may not be a part of the concept of burnout $[46,47]$. The present study found that PC providers with a temporary contract reported a lower degree of burnout, which was inconsistent with the findings of other studies $[19,26,44]$; this inconsistency may be due to the fact that the temporary contract group in this study included providers who have been rehired after retirement.

All three facility factors (including region, facility type and performance-based salary) were associated with burnout. Community health centres were more likely to have a higher level of burnout than township health centres. Related conclusions from previous studies were mixed $[23,26,48]$. Though some studies showed opposite results, the rapid urbanisation in China is challenging the health care system in urban cities because of the increasing population, which may add to workload of health care providers. Moreover, the higher level of job demand and the lower level of job control in large cities may also lead to burnout compared with small cities, towns or villages [48]. Performance-based salary was positively related to overall burnout, emotional exhaustion and depersonalisation. This finding may be due to the following two facts. Firstly, the government is using more process-oriented and volume-based indicators (e.g. number of outpatient visits and filling follow-up health records) rather than outcome-oriented ones to evaluate the performance of providers. The performance-based salary system was established in 2009, and it may lead to a higher degree of emotional exhaustion among PC providers [42, 49]. Secondly, the performance evaluation system focuses more on individual incentives rather than team-based ones, consequently increasing competition between colleagues and impacting peer relationships. This system may further lead to depersonalisation among PC providers. Therefore, we recommend that the performance-based salary system be transformed into a quality-based one, and teamwork incentives are needed to encourage collaboration [50].

This study has strength and limitations. A strong point of this study is that large samples of PC providers from six provinces have been surveyed. Moreover, to our knowledge, this is the first study to compare the job burnout between $\mathrm{CC}$ and $\mathrm{PH}$ service providers in China. With the multilevel linear regression model, we considered a nested data structure. However, we asked the participants to estimate the percentage of their participation in four types of services on a yearly basis, which may not result in a precise answer due to recall bias. However, this approach is more practical and understandable for PC providers in China, because job substitution is not a daily or monthly routine for many PC providers. For example, CC providers may participate in some health education activities that could be organised randomly within a year by PC facilities. Furthermore, although MBI-based instruments are the most widely used among a variety of measurements for job burnout, many different definitions of overall burnout prevalence and the prevalence of its subcomponents exist $[3,18]$. Thus, comparison between this study's results and those of other studies conducted in low-and middle-income countries must be interpreted with caution.

\section{Conclusions}

Job burnout is prevalent among different types of PC providers in China, thereby requiring action toward PC in general. More $\mathrm{PH}$ service providers are experiencing burnout than $\mathrm{CC}$ providers. Similar factors were associated with burnout among $\mathrm{CC}$ and $\mathrm{PH}$ service groups. We recommend strengthening the synergy between $\mathrm{CC}$ and $\mathrm{PH}$ services by increasing flexibility in care substitution, encouraging team work and integrating the financing systems. The organisational environment, which includes the incentive policy of the performance-based salary, affects job burnout in addition to workload and job type. We recommend that the performance-based salary system be transformed into a quality-based system that includes teamwork incentives. Younger, male and lowereducated PC providers and providers with an intermediate professional title or permanent contract were the high-risk groups. Further research is required to understand why burnout is higher among these specific groups and to ensure that effective support and coping strategies are provided. 


\section{Supplementary information}

Supplementary information accompanies this paper at https://doi. org/10.1186/s12960-020-00538-z.

Additional file 1. Roles of and services provided by clinical care and public health services providers. Additional file 1 presents a table showing the roles of and services provided by clinical care and public health services providers.

Additional file 2. Distribution of the percentage for clinical care, public health service providers and administrative group. Additional file 2 presents three tables showing the distribution of the percentage for clinical care $(n=13512)$, public health service providers $(n=4304)$ and administrative group ( $n=1170)$, respectively.

Additional file 3. Parameter coefficients and test of goodness-of-fit of multilevel models (null models). Additional file 3 presents a table showing the intra-class correlation coefficient in the null model and the goodnessof-fit indicator for each dependent variable.

\section{Abbreviations}

PC: Primary care; CC: Clinical care; PH: Public health; MBI-GS: Maslach Burnout Inventory-General Survey.

\section{Acknowledgements}

We thank our colleagues for their effort in the data collection and all local sites in our collaborative network for their participation in the investigation. Shan Lu gratefully acknowledges financial support from China Scholarship Council.

\section{Authors' contributions}

LS, ZL, KNS and KDS designed the study. LS and ZL acquired the data. LS conducted the statistical analysis and drafted the manuscript, which all authors substantially revised. All authors read and approved the final manuscript.

\section{Funding}

This research was funded by the National Natural Science Foundation of China (Grant no: 71734003). The organization had no role in the study design, data collection, analysis and interpretation and in writing the manuscript.

\section{Availability of data and materials}

The datasets used and/or analysed during the current study are available from the corresponding author on reasonable request.

\section{Ethics approval and consent to participate}

This study was approved by the ethics committee of Tongji Medical College, Huazhong University of Science and Technology (IORG No: IORG0003571). Before answering the questionnaire, all participants were assured de-identification and confidentiality in handling their data and consent to participate.

\section{Consent for publication}

Not applicable.

\section{Competing interests}

The authors declare that they have no competing interests.

\footnotetext{
Author details

${ }^{1}$ School of Medicine and Health Management, Tongji Medical College, Huazhong University of Science and Technology, Wuhan 430030, China. ${ }^{2}$ Research Centre for Rural Health Service, Key Research Institute of Humanities and Social Sciences of Hubei Provincial Department of Education, Wuhan 430030, China. ${ }^{3}$ Department of Public and Occupational Health, Amsterdam UMC, Amsterdam Public Health Research Institute, University of Amsterdam, Amsterdam, The Netherlands.
}

Received: 7 July 2020 Accepted: 20 November 2020 Published online: 03 December 2020

\section{References}

1. Starfield B, Shi L, Macinko J. Contribution of primary care to health systems and health. Milbank Q. 2005:83:457-502.

2. Kringos DS, Boerma W, van der Zee J, Groenewegen P. Europe's strong primary care systems are linked to better population health but also to higher health spending. Health Aff (Millwood). 2013;32:686-94.

3. Dugani S, Afari H, Hirschhorn LR, Ratcliffe H, Veillard J, Martin G, et al. Prevalence and factors associated with burnout among frontline primary health care providers in low- and middle-income countries: a systematic review. Gates Open Res. 2018;2:4.

4. National Health Commission of the People's Republic of China. China health statistical yearbook 2010. Beijing: Peking Union Medical College Publishing House; 2010

5. National Health Commission of the People's Republic of China. China health statistical yearbook 2018. Beijing: Peking Union Medical College Publishing House; 2018.

6. Lu S, Zhang L, Klazinga N, Kringos D. Evolution of the output-workforce relationship in primary care facilities in China from 2009 to 2017. Int J Environ Res Public Health. 2020;17:3043.

7. Maslach C, Jackson S, Leiter M. Maslach burnout inventory. 3rd ed. California: Consulting Psychologist Press; 1996.

8. Lo D, Wu F, Chan M, Chu R, Li D. A systematic review of burnout among doctors in China: a cultural perspective. Asia Pac Fam Med. 2018;17:3.

9. West CP, Tan AD, Habermann TM, Sloan JA, Shanafelt TD. Association of resident fatigue and distress with perceived medical errors. JAMA. 2009;302:1294-300.

10. Shanafelt TD, Balch CM, Bechamps G, Russell T, Dyrbye L, Satele D, et al. Burnout and medical errors among American surgeons. Ann Surg. 2010;251:995-1000

11. Maslach C. What have we learned about burnout and health? Psychol Health. 2001:16:607-11.

12. Poghosyan L, Clarke SP, Finlayson M, Aiken LH. Nurse burnout and quality of care: cross-national investigation in six countries. Res Nurs Health. 2010;33:288-98.

13. Shanafelt TD, Mungo M, Schmitgen J, Storz KA, Reeves D, Hayes SN, et al. Longitudinal study evaluating the association between physician burnout and changes in professional work effort. Mayo Clin Proc 2016:91:422-31.

14. Pantenburg B, Luppa M, König H-H, Riedel-Heller SG. Burnout among young physicians and its association with physicians' wishes to leave: results of a survey in Saxony, Germany. J Occup Med Toxicol. 2016;11:2.

15. Leiter MP, Maslach C. Nurse turnover: the mediating role of burnout. J Nurs Manag. 2009;17:331-9.

16. West CP, Dyrbye LN, Shanafelt TD. Physician burnout: contributors, consequences and solutions. J Intern Med. 2018;283:516-29.

17. Schaufeli WB, Maslach C, Marek T. Professional burnout : recent developments in theory and research. 1st ed. London: Routledge; 1993.

18. Rotenstein LS, Torre M, Ramos MA, Rosales RC, Guille C, Sen S, et al. Prevalence of burnout among physicians: a systematic review. JAMA. 2018;320:1131-50.

19. Li H, Yuan B, Meng Q, Kawachi I. Contextual factors associated with burnout among chinese primary care providers: a multilevel analysis. Int $J$ Environ Res Public Health. 2019;16:3555.

20. Bliese $\mathrm{P}$, Jex S. Incorporating a multilevel perspective into occupational stress research: theoretical, methodological, and practical implications. J Occup Health Psychol. 2002;7:265-76.

21. Xu W, Pan Z, Li Z, Lu S, Zhang L. Job Burnout Among Primary Healthcare Workers in Rural China: A Multilevel Analysis. Int J Environ Res Public Health. 2020;17.

22. Ge C, Fu J, Chang Y, Wang L. Factors associated with job satisfaction among Chinese community health workers: a cross-sectional study. BMC Public Health. 2011;11:884.

23. Zhang B, Zhang X, Zhao X, Tong X, Zhang N. Job Burnout of Medical Staff in Urban Community and Township Health Centers. Chin Hosp Managt. 2017;37:58-60. 
24. Wang H, Jin Y, Wang D, Zhao S, Sang X, Yuan B. Job satisfaction, burnout, and turnover intention among primary care providers in rural China: results from structural equation modeling. BMC Fam Pract. 2020;21:12.

25. Mao Y, Hu Y, Feng Z, Wang R, Chen X, Zhang W, et al. Job burnout and correlated factors of three-tiered public health workers: a cross-sectional study in China. Health Soc Care Commun. 2020;28:1241-51.

26. Gan Y, Jiang H, Li L, Yang Y, Wang C, Liu J, et al. Prevalence of burnout and associated factors among general practitioners in Hubei, China: a crosssectional study. BMC Public Health. 2019;19:1607.

27. Yang S, Liu D, Liu H, Zhang J, Duan Z. Relationship of work-family conflict, self-reported social support and job satisfaction to burnout syndrome among medical workers in southwest China: a cross-sectional study. PLoS ONE. 2017:12:e0171679.

28. Li C, Shi K. The influence of distributive justice and procedural justice on job burnout. Acta Psychologica Sinica. 2003;35:677-84.

29. Wen J, Cheng Y, Hu X, Yuan P, Hao T, Shi Y. Workload, burnout, and medical mistakes among physicians in China: a cross-sectional study. BioScience Trends. 2016;10:27-33.

30. Fang $P$, Liu $X$, Huang $L$, Zhang $X$, Fang Z. Factors that influence the turnover intention of Chinese village doctors based on the investigation results of Xiangyang City in Hubei Province. Int J Equity Health. 2014;13:84.

31. Ahola K, Gould R, Virtanen M, Honkonen T, Aromaa A, Lönnqvist J. Occupational burnout as a predictor of disability pension: a population-based cohort study. Occup Environ Med. 2009;66:284-90.

32. Kalimo R, Pahkin K, Mutanen P, Toppinen-Tanner S. Staying well or burning out at work: Work characteristics and personal resources as long-term predictors. Work Stress. 2003;17:109-22.

33. Chen $\mathrm{K}-\mathrm{Y}$, Yang $\mathrm{C}-\mathrm{M}$, Lien $\mathrm{C}-\mathrm{H}$, Chiou $\mathrm{H}-\mathrm{Y}$, Lin $\mathrm{M}-\mathrm{R}$, Chang $\mathrm{H}-\mathrm{R}$, et al. Burnout, job satisfaction, and medical malpractice among physicians. Int J Med Sci. 2013;10:1471-8.

34. Yang J, Zhang L. Relationship of job burnout and turnover intention of township hospital doctors in a country. Chin Med Ethics. 2015;28:279-83.

35. Wang F, Xu L, Xie Z, Zhang T. Status of regional distribution for job burnout of clinicians in China. Chin Gen Pract. 2013;16:3006-11.

36. Sun $X$, Di Y, Kong $P$, Jiang $X$, Wang H, Meng $Q$. Analysis on job burnout and related determinants among primary care providers in China. Chin J Health Policy. 2012;5:26-31.

37. Li X, Lu J, Hu S, Cheng K, De Maeseneer J, Meng Q, et al. The primary health-care system in China. Lancet. 2017;390:2584-94.

38. Wu D, Lam TP. Underuse of primary care in China: the scale, causes, and solutions. J Am Board Fam Med. 2016;29:240-7.
39. Yip WC-M, Hsiao WC, Chen W, Hu S, Ma J, Maynard A. Early appraisal of China's huge and complex health-care reforms. Lancet. 2012;379:833-42.

40. Zhang M, Wang W, Millar R, Li G, Yan F. Coping and compromise: a qualitative study of how primary health care providers respond to health reform in China. Hum Resour Health. 2017;15:1-12.

41. Kieft RA, de Brouwer BB, Francke AL, Delnoij DM. How nurses and their work environment affect patient experiences of the quality of care: a qualitative study. BMC Health Serv Res. 2014;14:249.

42. Yuan B, Balabanova D, Gao J, Tang S, Guo Y. Strengthening public health services to achieve universal health coverage in China. BMJ. 2019;365:12358.

43. Toppinen-Tanner S. Process of burnout: structure, antecedents, and consequences. Helsinki: Finnish Institute of Occupational Health; 2011. Report No:: 93.

44. Wang Z, Xie Z, Dai J, Zhang L, Huang Y, Chen B. Physician burnout and its associated factors: a cross-sectional study in Shanghai. J Occup Health. 2014;56:73-83.

45. Maslach C, Leiter MP. Understanding the burnout experience: recent research and its implications for psychiatry. World Psychiatry 2016:15:103-11.

46. Schaufeli WB, Bakker AB, Hoogduin K, Schaap C, Kladler A. On the clinical validity of the Maslach burnout inventory and the burnout measure. Psychol Health. 2001;16:565-82.

47. Schutte N, Toppinen S, Kalimo R, Schaufeli W. The factorial validity of the Maslach Burnout Inventory-General Survey (MBI-GS) across occupational groups and nations. J Occup Org Psychol. 2000;73:53-66.

48. Saijo Y, Chiba S, Yoshioka E, Kawanishi Y, Nakagi Y, Ito T, et al. Job stress and burnout among urban and rural hospital physicians in Japan. Aust J Rural Health. 2013;21:225-31.

49. Ma X, Wang H, Yang L, Shi L, Liu X. Realigning the incentive system for China's primary healthcare providers. BMJ. 2019;365:I2406.

50. Greene J, Kurtzman ET, Hibbard JH, Overton V. Working under a cliniclevel quality incentive: primary care clinicians' perceptions. Ann Fam Med. 2015;13:235-41.

\section{Publisher's Note}

Springer Nature remains neutral with regard to jurisdictional claims in published maps and institutional affiliations.
Ready to submit your research? Choose BMC and benefit from:

- fast, convenient online submission

- thorough peer review by experienced researchers in your field

- rapid publication on acceptance

- support for research data, including large and complex data types

- gold Open Access which fosters wider collaboration and increased citations

- maximum visibility for your research: over $100 \mathrm{M}$ website views per year

At BMC, research is always in progress.

Learn more biomedcentral.com/submissions 